\title{
Advancing Research Methods for Common Problems in Family Medicine and Family Medicine Practice Management
}

\author{
Marjorie A. Bowman, MD, MPA and Dean A. Seebusen, MD, MPH
}

Several research groups from multiple institutions provide structure and methods to improve research for family medicine. Colon cancer research includes which common screening test for colon cancer most often results in completed colonoscopy. Authors explore how some cardiovascular preventive medications are overused while others are underused. Three research papers specifically advance improvements for practice management, 3 articles address diabetes, 3 others cover family physicians caring for specific populations (pregnant women, children, and those with sports-related issues).

There are practical research articles on practice management and others on common clinical problems. This issue also includes a clinical review on acute sensorineural hearing loss and human papilloma virus immunization guidelines that can cause confusion. ( $\mathrm{J}$ Am Board Fam Med 2021;34:1-3.)

\section{Advancing Family Medicine Research}

We start this issue with advances for undertaking research in primary care. Such research is very important, and yet, as a group of international primary care researchers and users of primary care research report, it can be difficult to find (or understand) the primary care research that exists. ${ }^{1}$ To fill a gap in the literature, Yawn et $\mathrm{al}^{2}$ present the plans for an international prospective observational study of 3,000 patients with chronic obstructive pulmonary disease (COPD) across 5 organizations and multiple countries. Two articles are specific to practice transformation research. Leaders of eight EvidenceNOW practice transformation research projects (funded by Agency for Healthcare Research Quality) have created a taxonomy to assist those working on practice transformation-from researchers, to private practices, to health systems. ${ }^{3}$ Another group of authors from EvidenceNOW identified factors related to clinician engagement with practice quality improvement across 195 practices. $^{4}$

Other researchers report on their development of a practical, helpful electronic health record mechanism to identify potential subjects eligible for colonoscopy research. ${ }^{5}$ The need for more colon cancer-related research is evident in the careful study from Cooper et $\mathrm{al}^{6}$ on which colon cancer abnormal test (FIT or mt-sDNA) results in greater

Conflict of Interest: The authors are editors of the $\mathcal{F} A B F M$. colonoscopy uptake. There are a variety of differences in the tests, such as how they are done, and the mechanism of followup. Positive FIT followup was lower, but the test might have been used in different circumstances. Of the colonoscopies done, the rate of abnormal findings was substantial, and the results provide hints at what could be done to ensure adequate followup.

\section{Practice Management and Improvement Reports}

Medical scribes are increasingly utilized in practices. Zallman et $\mathrm{al}^{7}$ tackled an important question on what efficiencies can be gained when medical scribes are used by investigating the burden of tasks that occur outside of the visit.

While one might think we know the range of activities are accomplished in primary health care, the change to capitation in Oregon's Medicaid program offered a wonderful opportunity to clarify common aspects of care that are often not tracked. Specifically, 18 visit and non-visit-based care activities, "Care Services That Engage Patients," were defined and tracked. ${ }^{8}$ While the report is based in Community Health Centers, the definitions could be applied more broadly, and the impact data of interest to many.

Primary care physicians are the largest group prescribing long-term medication therapy for opioid addiction. Stephens et $\mathrm{al}^{9}$ investigate practice-based 
tracking and monitoring of the participating patients to maximize their outcomes. And Smith et $\mathrm{al}^{10}$ report the experience of one practice's attempts to decrease opioid use-their significant success and the characteristics of patients who remained on long-term opioid replacement therapy.

Pharmaceutical industry interaction at the residency level is changing, consistent with the changing advertising methods in the industry. ${ }^{11}$

\section{Cardiovascular Disease and its Treatment}

Statin drugs are among the most commonly prescribed medications and are known to reduce adverse cardiovascular outcome. Yet, many patients with clear indications are not on statins. Some is due to patient factors, but there are also clinician factors for not prescribing statins, such as overly complicated or changing guidelines, as noted in this study involving 45 practices across 8 states and the records of 223,289 patients. $^{12}$ Non-adherence to medication prevents individuals from maximizing their health and is quite common. Working with focus groups, Tarn et $\mathrm{a}^{13}$ identify the common thoughts from patients that inform how clinicians could interact with patients in order to increase the likelihood of statin adherence.

Low-dose aspirin is another medication that can help prevent adverse cardiovascular outcomes. Many older African-American adults take aspirin without a prescription. Bazargan et $\mathrm{al}^{14}$ provide additional clarifying information. Clearly the high rate of use indicates the need for more discussion between patients and their clinicians.

\section{Practical Patient Care in Family Medicine}

The recognition and management of 2 acute conditions are presented. While sudden sensorineural hearing loss is uncommon, it is the type of diagnosis that requires rapid evaluation and intervention for optimal outcomes. ${ }^{15}$ Finger et $\mathrm{al}^{16}$ discuss the need (or lack thereof) for chest radiographs when adults are seen for acute chest pain or trauma.

We have several articles with information on how to prevent diabetes and its complications. Miller-Rosales et $\mathrm{al}^{17}$ report on multidisciplinary diabetes care in community health centers, including patient interactions and outcomes. Prediabetes status awareness is compared to patient health behaviors in the paper by $\mathrm{Li}$ et al. ${ }^{18}$ To prevent diabetes, routine screening for diabetic retinopathy is indicated, and Farford et a ${ }^{19}$ investigate family physician office screening by retinal camera.

Human Papilloma Virus (HPV) immunization is now routine for many people under the age of 26. However, the recommendations by Advisory Committee on Immunization Practices have changed to add a recommendation for shared clinical decision making for adults age 27 to 45 years. This survey of primary care physicians shows interest in giving the vaccine, but some confusion on the facts. ${ }^{20}$

Groups visits for Advance Care Planning for patients with heart failure and their caregivers were well received. ${ }^{21}$

\section{Family Physician Care of Specific Populations}

Family physicians providing obstetric care prevent "obstetrical deserts" by providing C-sections in rural areas $^{22}$ where there are fewer obstetricians. Yet, despite higher risk related to negative social determinants of health, obstetric outcomes by a family medicine department were similar to the obstetrics department. ${ }^{23}$ Nagle et al $^{24}$ report on provision of early pregnancy loss care in New York Federally Qualified Health Centers.

In another clinical area that many family physicians pursue is sports medicine. Nithyanandam et $\mathrm{al}^{25}$ identify differences between the practices of those sports medicine certified family physicians who spend more than three quarters of their time practicing sports medicine compared with those who spend less time. Also, despite rumors otherwise, most family physicians do see pediatric patients. Specifics can be found in the report of Jetty et al. ${ }^{26}$

Sadly, even after the Affordable Care Act provided insurance to those previously uninsured, many parents report not getting care for their child due to underinsurance. ${ }^{27}$

To see this article online, please go to: http://jabfm.org/content/ 34/1/1.full.

\section{References}

1. Phillips WR, Sturgiss E, Hunik L, et al. Improving the reporting of primary care research: an international survey of researchers. J Am Board Fam Med 2021;34:12-21.

2. Yawn BP, Kaplan A, Pace WD, et al. Advancing the Patient EXperience (APEX) in COPD registry: 
study design and strengths. J Am Board Fam Med 2021;34:22-31.

3. Solberg LI, Kuzel A, Parchman ML, et al. A taxonomy for external support for practice transformation. J Am Board Fam Med 2021;34:32-39.

4. Soylu TG, Cuellar AE, Goldberg DG, Kuzel AJ. Engagement of small to medium-sized primary care practices in quality improvement efforts. J Am Board Fam Med 2021;34:40-48.

5. Daly JM, Parang K, Levy BT. Electronic health record algorithm development for research subject recruitment using colonoscopy appointment scheduling. J Am Board Fam Med 2021;34:49-60.

6. Cooper GS, Grimes A, Werner J, Cao S, Fu P, Stange KC. Barriers to follow-up colonoscopy after positive FIT or multitarget stool DNA testing. J Am Board Fam Med 2021;34:61-69.

7. Zallman L, Altman W, Chu L, et al. Do medical scribes help primary care providers respond more quickly to out-of-visit tasks? J Am Board Fam Med 2021;34:70-77.

8. Cottrell EK, Dambrun K, O'Malley J, et al. Documenting new ways of delivering care under Oregon's alternative payment and advanced care model. J Am Board Fam Med 2021;34:78-88.

9. Stephens KA, Ike B, Baldwin LM, Packer C, Parchman M. Challenges and approaches to population management of long-term opioid therapy patients. J Am Board Fam Med 2021;34:89-98.

10. Smith AY, Kirk JK, Smith PF, Wells BJ. Mental health and benzodiazepine use among patients on chronic opioid therapy. J Am Board Fam Med 2021;34:99-104.

11. Brown SR, Fugh-Berman A. Changing pharmaceutical industry interaction in U.S. family medicine residencies: a CERA study. J Am Board Fam Med 2021;34:105-112.

12. Tong ST, Sabo RT, Hochheimer CJ, et al. Uptake of statin guidelines to prevent and treat cardiovascular disease. J Am Board Fam Med 2021;34:113-122.

13. Tarn DM, Barrientos M, Pletcher MJ, et al. Perceptions of patients with primary nonadherence to statin medications. J Am Board Fam Med 2021;34:123-131.

14. Bazargan M, Wisseh C, Adinkrah E, Boyce S, King EO, Assari S. Low-dose aspirin use among AfricanAmerican older adults. J Am Board Fam Med 2021;34:132-143.

15. Prince ADP, Stucken EZ. Sudden sensorineural hearing loss: a diagnostic and therapeutic emergency. J Am Board Fam Med 2021;34:216-223.
16. Nishimura E, Finger A, Harris M, Yoon HC. Oneview chest radiograph for initial management of most ambulatory patients with rib pain. J Am Board Fam Med 2021;34:144-150.

17. Miller-Rosales C, Rodriguez HP. Interdisciplinary primary care team expertise and diabetes care management. J Am Board Fam Med 2021;34:151-161.

18. Li E, Silverio A, Cunningham A, LaNoue MD, Mills G. Association of prediabetes status awareness with behaviors and perception of health. J Am Board Fam Med 2021;34:224-230.

19. Farford BA, Ahuja AS, Stewart MW, Naessens JM, Keith JJ. Screening for diabetic retinopathy with a nonmydriatic ultra-wide-field retina camera by family medicine physicians. J Am Board Fam Med 2021;34:231-237.

20. Hurley LP, O'Leary ST, Markowitz LE, et al. US primary care physicians' viewpoints on HPV vaccination for adults 27-45 years. J Am Board Fam Med 2021;34:162-170.

21. Bandini JI, Coulourides KA, Olsen B, et al. Feasibility of group visits for advance care planning among patients with heart failure and their caregivers. J Am Board Fam Med 2021;34:171-180.

22. Tong ST, Eden AR, Morgan ZJ, Bazemore AW, Peterson LE. The essential role of family physicians in providing cesarean sections in rural communities. J Am Board Fam Med 2021;34:10-11.

23. Partin M, Sanchez A, Poulson J, Berg A, Parascando J, Ines Ramirez S. Social inequities between prenatal patients in family medicine and obstetrics and gynecology with similar outcomes. J Am Board Fam Med 2021;34:181-188.

24. Nagle A, Srinivasulu S, Maldonado L, deFiebre G. Provision of early pregnancy loss care in New York federally qualified health centers. J Am Board Fam Med 2021;34:238-242.

25. Nithyanandam S, Peterson LE, Puffer JC. Factors associated with time spent practicing sports medicine by those with a certificate of added qualification. J Am Board Fam Med 2021;34:189-195.

26. Jetty A, Romano MJ, Jabbarpour Y, Petterson S, Bazemore A. A cross-sectional study of factors associated with pediatric scope of care in family medicine. J Am Board Fam Med 2021;34:196207.

27. Pascoe JM, Stolfi A, Eberhart G, Khamis H. Parents' report of their children's underinsurance status after the Affordable Care Act. J Am Board Fam Med 2021;34:208-215. 